- Letter

\title{
Letter to the Editor Regarding the Article: Relationship between Age at Menarche and Metabolic Syndrome in Premenopausal Women: Korea National Health and Nutrition Examination Survey 2013-2014
}

\author{
Anthony Urteaga ${ }^{1, *}$, Miluska Robles ${ }^{1}$, Alonso Soto ${ }^{1,2}$ \\ ${ }^{1}$ Escuela de Medicina, Universidad Peruana de Ciencias Aplicadas, Lima, Perú \\ ${ }^{2}$ Departamento de medicina, Hospital Nacional Hipólito Unanue, Lima, Perú
}

\section{Dear Editor,}

We read with great interest the article by Hwang et al. ${ }^{1)}$ published in the September 2018 issue of the Korean Journal of Family Medicine.

The paper reported lack of an association between the age of menarche and metabolic syndrome in the Korean population as compared to other populations. ${ }^{2-4)}$ However, we have some comments regarding the methodological issues.

First, we believe that by stratifying the multivariate analysis by age (20-39 and $40-55$ years) as a categorical variable at the time of survey and then adjusting all models again using age as a numerical variable (see Table 3 in the study of Hwang et al. ${ }^{1)}$ ), the models would be overadjusted, which can affect the variations by falsely increasing the confidence intervals. ${ }^{2)}$ This could explain why strong relationships with metabolic syndrome were not found in the multivariate analysis, contrary to the finding from the crude analysis, where women with menarche at younger than 12 years were found to have two times higher risk of developing a metabolic syndrome than women with ages of menarche between 12 and 15 years, as shown in Appendix 1 of Hwang et al. ${ }^{1)}$ The later association is consistent with findings of multiple previous studies.

Another remarkable finding is that although the risk of metabolic syndrome is almost twice as high in patients in the menarche group who were older than 16 years than in those in the menarche group who were younger than 12 years, the data in Table 2 of Hwang et al. ${ }^{1)}$ show the frequency of individual values such as body mass index and abdominal circumference, which have a higher prevalence in women younger than 12 years. An explanation of this difference should have been provided in the Discussion section.

\section{CONFLICT OF INTEREST}

No potential conflict of interest relevant to this article was reported.

\section{ORCID}

Anthony Urteaga: https://orcid.org/0000-0003-0227-1819

Miluska Robles: https://orcid.org/0000-0003-2162-4835

Alonso Soto: https://orcid.org/0000-0001-8648-8032

Received: December 17, 2018, Accepted: December 19, 2018 


\section{REFERENCES}

1. Hwang YS, Park EJ, Choi JG, Kim HE, Park SG, Yoo SM. Relationship between age at menarche and metabolic syndrome in premenopausal women: Korea National Health and Nutrition Examination Survey 2013-2014. Korean J Fam Med 2018;39:300-6.

2. Stockl D, Meisinger C, Peters A, Thorand B, Huth C, Heier M, et al. Age at menarche and its association with the metabolic syndrome and its components: results from the KORA F4 study. PLoS One 2011;6: e26076.

3. Heys M, Schooling CM, Jiang C, Cowling BJ, Lao X, Zhang W, et al. Age of menarche and the metabolic syndrome in China. Epidemiology 2007;18:740-6.

4. Zheng Y, Zhang G, Chen Z, Zeng Q. Association between age at menarche and cardiovascular disease risk factors in China: a large population-based investigation. Cardiorenal Med 2016;6:307-16. 